Available online at GSC Online Press Directory

GSC Advanced Research and Reviews e-ISSN: 2582-4597, CODEN (USA): GARRC2

Journal homepage: https://www.gsconlinepress.com/journals/gscarr

(RESEARCH ARTICLE)

\title{
Synthesis, characterization and chelating properties of tannin-8-hydroxy quinoline - formaldehyde polymer
}

Sasikala T *, Greeshma KP, Gnana Priya K, Muthulingam S and Nandhakumar C

Department of Chemistry, Sri Ramakrishna College of Arts and Science (SRCAS), Coimbatore - 641006.

Publication history: Received on 29 September 2020; revised on 22 October 2020; accepted on 24 October 2020

Article DOI: https://doi.org/10.30574/gscarr.2020.5.2.0083

\begin{abstract}
Tannin obtained from Eucalyptus plant, condensed with formaldehyde and then 8-hydroxy quinoline. The so called obtained polymer designated as TFQ was used for metal chelate formation. Thus Transition metal chelates of TFQ with $\mathrm{Zn}^{+2}, \mathrm{Co}^{+2}, \mathrm{Cu}^{+2}, \mathrm{Ni}^{+2}$ and $\mathrm{Mn}^{+2}$ metal ions were prepared. The ligand TFQ and its all five metal chelates were characterized by nitrogen content, IR, UV-Visible spectral studies, magnetic moments and thermogravimetry. The antimicrobial activity of all the samples has also been monitored against common microbes.
\end{abstract}

Keywords: Tannin; 8-hydroxy Quinoline; Metal Chelates; Spectral Study; Thermogravimetry and Magnetic Moments.

\section{Introduction}

Considered research has targeted on natural materials like Tannin, to develop biobased materials [1-3]. Tannin is common material extracting from plants which contain high amount of polyphenols [4,5] its common structure is as follows

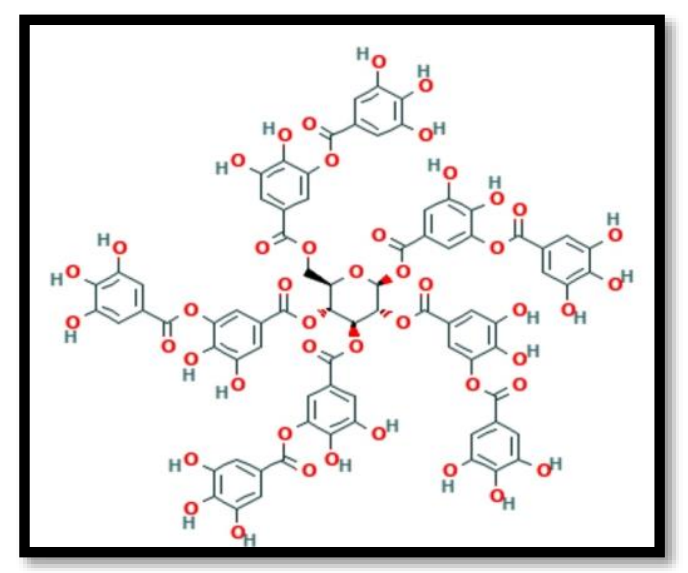

Figure 1 Structure of Tannin

Tannin is pivotal materials for various industries like leather, textile, coating, cosmetic etc. Recently the Tannin based copolymer resins are reported [5].

\footnotetext{
* Corresponding author: Sasikala T

Department of Chemistry, Sri Ramakrishna College of Arts and Science (SRCAS), Coimbatore - 641006.
}

Copyright (@ 2020 Author(s) retain the copyright of this article. This article is published under the terms of the Creative Commons Attribution Liscense 4.0. 
Having phenolic group and tendency to condense with formaldehyde, the present authors thought to explore the field to metal chelating resin based on Tannin. Thus the present communication comprises the synthesis of Tanninformaldehyde-8-hydroxy quinoline (TFQ) copolymer and study of its chelating properties. The work is scanned in scheme - 1 .

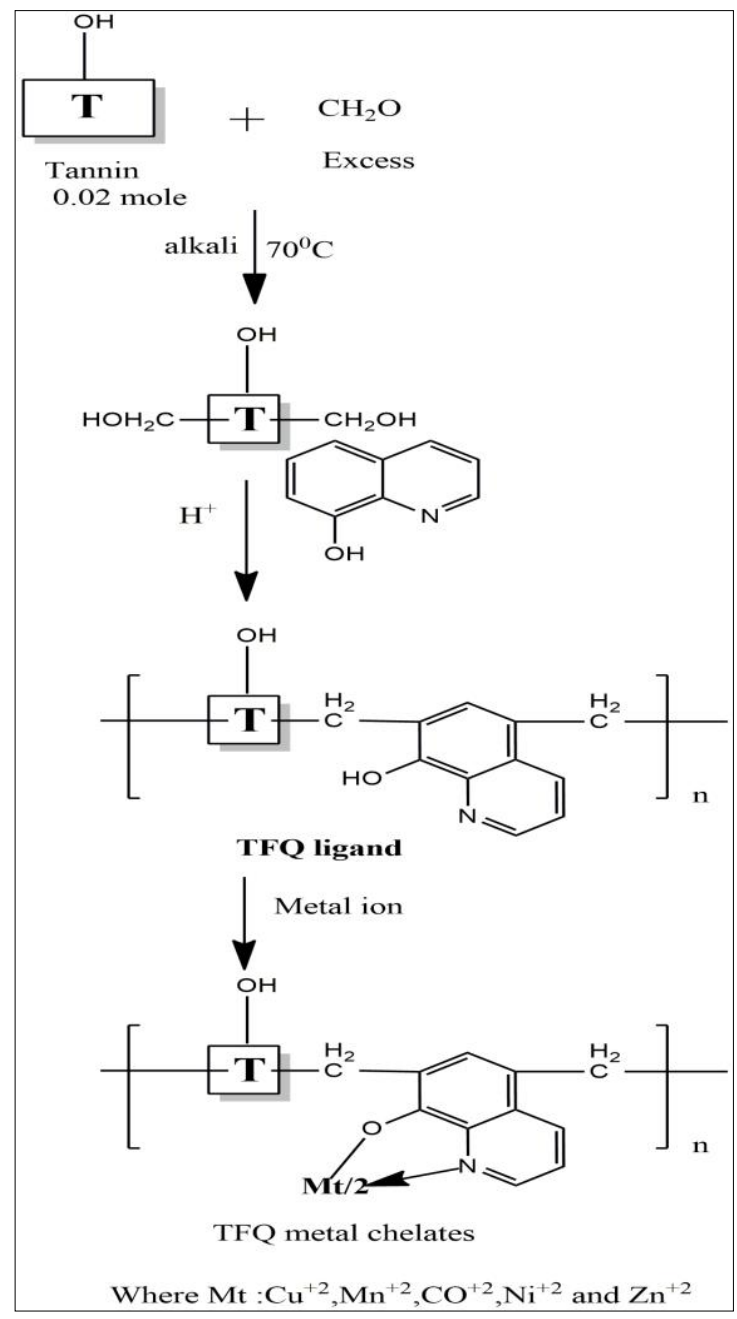

Figure 2 Scheme of the synthesis of Tannin-formaldehyde-8-hydroxy quinoline

\section{Material}

Tannin was extracted from Eucalyptus bark and leaves. It was used as dry form. All other chemicals were used as analytical pure grade.

\subsection{Measurements}

Nitrogen content of all the samples was determined on colman analyzer. The infrared spectra (FT-IR) were recorded in the range $4000-400 \mathrm{~cm}^{-1}$ with a Perkin Elmer spectrum GX spectrophotometer (FT-IR) instrument using KBr pallets. The metal content of polymeric chelates was carried out by EDTA titration method as reported in literature [6]. Magnetic moment of all polymeric chelates determined at room temperature using Gouy method reported in literature [18]. The reflectance spectra of all polymeric metal chelates were recorded on Backman spectrophotometer. TG Analysis of polymeric chelates was determined on Du Pont 950 thermogravimetric analyzer at $10^{\circ} \mathrm{K}$ per minutes $[7,8]$.

\subsection{Synthesis of Tannin-Formaldehyde-8-hydroxy Quinoline copolymer (TFQ)}

In a round bottom flask Tannin powder (34g, 0.02 mole) and formaldehyde $(37 \% \mathrm{w} / \mathrm{v}$ ) solution in $1 \%$ aqueous $\mathrm{NaOH}$ solution $(200 \mathrm{ml})$ was heated on boiling water bath. The resultant resinous mass was neutralized by dil. HCl. To this resin solution 8-hydroxy quinoline ( $54.5 \mathrm{~g}, 0.5 \mathrm{~mole}$ ) in dil. $\mathrm{HCl}$ was added and reflux for 3 hrs. The dark brown mass was 
obtained. The mass was neutralized by aq. ammonia. The product was filtered, washed and air dried. Yield was $85 \%$.It was soluble in DMF and DMSO solvent. It did not melt upto $300^{\circ} \mathrm{C}$.

[The Tannin: 8-hydroxy quinoline ratio taken at unimolar hydroxy group]

\subsection{Synthesis of Polymeric Chelates of TFQ}

The polymeric metal chelates viz. $\mathrm{Cu}^{2+}, \mathrm{Ni}^{2+}, \mathrm{Co}^{2+}, \mathrm{Mn}^{2+}$ and $\mathrm{Zn}^{2+}$ of TFQ ligand was synthesized as follow:

Polymeric TFQ ligand solution (0.01 mole) was prepared using 20\% formic acid and further warm for 10 min on water bath. Then warm metal salt solution ( 0.01 mole) prepared in $50 \%$ aqueous formic acid was added gradually to above prepared solution with constant stirring. The resulting product was made alkaline using dil. $\mathrm{NH}_{3}$ solution till the polymeric metal chelate formed. It was further heated on water bath for complete coagulation. The ppts were filtered,washed with DMF and air dried. The synthesized polymeric chelats were designated as M(II) TFQ. The characterization of all polymeric chelates was displayed in Table -1 .

\section{Results and discussion}

TFQ was obtained in form of pale dark brown powder and soluble in DMF and DMSO.N and metal content analyses results of TFQ and their metal chelates are provided in Table-1 which consistent with the predicted structure as shown in above Scheme-1. The polymeric chelates of TFQ ligand with various metals such viz. $\mathrm{Cu}^{2+}, \mathrm{Ni}^{2+}, \mathrm{Co}^{2+}, \mathrm{Mn}^{2+}$ and $\mathrm{Zn}^{2+}$ were also obtained with good yield.

Table 1 Elemental analyses of TFQ and its metal chelates

\begin{tabular}{|l|l|l|l|l|}
\hline \multirow{2}{*}{$\begin{array}{l}\text { Designation } \\
\text { of sample }\end{array}$} & \multicolumn{4}{|l|}{ Elemental analyses (\%) } \\
\cline { 2 - 5 } & N & \multicolumn{2}{l|}{ M2+ } \\
\cline { 2 - 5 } & Cal. & Found & Cal. & Found \\
\hline TF & - & - & - & - \\
\hline TFQ & 3.41 & 3.37 & - & - \\
\hline Cu2+TFQ & 3.17 & 3.14 & 7.19 & 7.20 \\
\hline Ni2+TFQ & 3.19 & 3.13 & 6.68 & 6.60 \\
\hline Co2+TFQ & 3.19 & 3.15 & 6.71 & 6.65 \\
\hline Mn2+TFQ & 3.20 & 3.12 & 6.28 & 6.22 \\
\hline Zn2+TFQ & 3.16 & 3.14 & 7.39 & 7.35 \\
\hline
\end{tabular}

IR spectra of synthesized TFQ ligand show a broad band in the range $3350-3385 \mathrm{~cm}^{-1}$ due to OH stretching of Tannin and 8-hydroxy quinoline derivative which confirms presence of 8-HQ nucleus. Also the characteristics bands were found at $1445,1426,1514$ and $1610 \mathrm{~cm}^{-1}$ further supports here presence of 8-hydroxy quinoline derivative. The aliphatic C-O of ether group was found at 1070 and $1167 \mathrm{~cm}^{-1}$ while weak bands at 2720 and $2832 \mathrm{~cm}^{-1}$ attributes to aliphatic $-\mathrm{CH}_{2}$ groups. Also other typical bands 8-quinolinol was found at their respective positions as reported earlier [6]. The IR spectra of metal chelates resemble each other with only difference found in bands of metal-ligand bonding.

The comparison of IR spectrum of ligand and their metal chelates has not shown any characteristic because there are number of hydroxyl groups present in Tannin. So the interpretation at complexation is not rectified. However it is fact the metal content confirm the chelation. Also the formation of M-O bonds was confirms by bands found at $1100 \mathrm{~cm}^{-1} \mathrm{due}$ to C-O-M stretching frequency [9]. Another band is shifted to lower frequency (about 20-30 cm-1) than found in its parent ligand.

The diffuse electronic spectrum of $\mathrm{Cu}^{2+}$ chelates shows two broad bands around 14120 and $23758 \mathrm{~cm}^{-1}$. The first band may be due to a ${ }^{2} \mathrm{~T}_{1 \mathrm{~g}} \rightarrow{ }^{2} \mathrm{~F}_{\mathrm{g}}$ transition, while the second band may be due to charge transfer. The band along with magnetic moment value found at $1.85 \mathrm{BM}$ suggests a distorted octahedral structure for the $\mathrm{Cu}^{2+}$ metal chelates [8]. As the spectrum of the metal chelate of $\mathrm{Ni}^{+2}$ show two distinct bands at 15165 and $23574 \mathrm{~cm}-1$ are assigned as ${ }^{3} \mathrm{~A}_{1 \mathrm{~g}} \rightarrow{ }^{3} \mathrm{~T}_{1 \mathrm{~g}(\mathrm{~F})}$, and ${ }^{3} \mathrm{~A}_{1 \mathrm{~g}} \rightarrow$ 
${ }^{3} \mathrm{~T}_{1 \mathrm{~g}}(\mathrm{P})$ transitions, respectively suggested the octahedral environment for $\mathrm{Ni}+2$ ion and further supported by magnetic moment value found at $3.15 \mathrm{BM}$ [10]. The $\mathrm{Co}^{2+}$ metal chelate shows two absorption bands at 22556 and $15235 \mathrm{~cm}^{-1}$, which can be assigned ${ }^{4} \mathrm{~T}_{1 \mathrm{~g}} \rightarrow{ }^{2} \mathrm{~T}_{2 \mathrm{~g}},{ }^{4} \mathrm{~T}_{1 \mathrm{~g}} \rightarrow{ }^{4} \mathrm{~T}_{1 \mathrm{~g}}(\mathrm{P})$ transitions, respectively. The found reflectance bands and the magnetic moment value i.e. 4.12BM indicate an octahedral geometry for $\mathrm{Co}^{+2}$ metal chelate [11]. The spectrum of $\mathrm{Mn}^{2+}$ polymeric chelate consist two bands at $18028 \mathrm{~cm}^{-1}$ and $24870 \mathrm{~cm}^{-1}$ may be assigned to ${ }^{6} \mathrm{~A}_{1 \mathrm{~g}} \rightarrow{ }^{4} \mathrm{~T}_{2 \mathrm{~g}(\mathrm{G})}$ and ${ }^{6} \mathrm{~A}_{1 \mathrm{~g}} \rightarrow{ }^{4} \mathrm{~A}_{2 \mathrm{~g}(\mathrm{G})}$ transitions, respectively. The high intensity of the bands and magnetic moment value at $5.02 \mathrm{BM}$ suggests the octahedral geometry for $\mathrm{Mn}^{+2}$ chelate [12]. The magnetic moment values revealed paramagnetic nature for all metal chelates except the $\mathrm{Zn}^{+2}$ chelate which is diamagnetic in nature.

The TG analyses of TFQ and polymeric chelates were carried out to study the thermal behavior. The all results are displayed in Table-2. Examination of these results shows the single step degradation in the temperature range of 300$400^{\circ} \mathrm{C}$ while $400-500^{\circ} \mathrm{C}$ the wt. loss is found almost around $90 \%$ for the TFQ ligand. Similarly the single step degradation was in the temperature range of $300-400^{\circ} \mathrm{C}$ while $550^{\circ} \mathrm{C}$ the wt. loss is found almost around $90 \%$ for the TFQ. The decomposing rate in all polymeric metal chelates were found initially low up to $200^{\circ} \mathrm{C}$ and then increases to maximum at the range $400-500 \mathrm{C}$. The thermal stability order of polymeric chelates is as follows: $\mathrm{Cu}^{+2}-\mathrm{TFQ}>\mathrm{Co}^{+2}-\mathrm{TFQ}>\mathrm{Mn}+2-\mathrm{TFQ}>$ $\mathrm{Ni}^{+2}-\mathrm{TFQ}-\mathrm{TFQ}>\mathrm{Zn}^{+2}-\mathrm{TFQ}$.

Table 2 TGA analyses TFQ and its metal chelates

\begin{tabular}{|l|l|l|l|l|l|l|}
\hline \multirow{2}{*}{ Sample } & \multicolumn{7}{|c|}{ \% Wt. loss at Temp( $\left.{ }^{\circ} \mathbf{C}\right)$} \\
\cline { 2 - 7 } & $\mathbf{1 0 0}$ & $\mathbf{2 0 0}$ & $\mathbf{3 0 0}$ & $\mathbf{4 0 0}$ & $\mathbf{5 0 0}$ & $\mathbf{6 0 0}$ \\
\hline $\mathrm{TFQ}$ & 2 & 5 & 20 & 38 & 70 & 78 \\
\hline $\mathrm{Cu}^{2+} \mathrm{TFQ}$ & 4 & 7 & 12 & 35 & 68 & 74 \\
\hline $\mathrm{Ni}^{2+} \mathrm{TFQ}$ & 5 & 8 & 14 & 39 & 72 & 78 \\
\hline $\mathrm{Co}^{2+} \mathrm{TFQ}$ & 7 & 10 & 15 & 45 & 86 & 90 \\
\hline $\mathrm{Mn}^{2+} \mathrm{TFQ}$ & 5 & 10 & 14 & 48 & 80 & 87 \\
\hline $\mathrm{Zn}^{2+} \mathrm{TFQ}$ & 7 & 12 & 18 & 65 & 92 & 95 \\
\hline
\end{tabular}

Antifungal activity of all the samples was monitored against various fungi, following the method reported in literature [13]. The examination of antifungal shown in Table-3 suggests that the ligand is moderately toxic against fungi, while all the chelates are more toxic than ligand. Among the all synthesized polymeric chelates $\mathrm{Cu}^{+2}$ chelate found more toxic against fungi [14].

Table 3 Antifungal activity of TFQ and its metal chelates

\begin{tabular}{|l|l|l|l|l|}
\hline \multirow{2}{*}{ Sample } & \multicolumn{4}{|l|}{ Zone of inhibition of fungus at 1000 ppm (\%) } \\
\cline { 2 - 5 } & $\begin{array}{l}\text { Asperginus } \\
\text { niger }\end{array}$ & $\begin{array}{l}\text { Botrydeplaia } \\
\text { thiobromine }\end{array}$ & $\begin{array}{l}\text { Nigrospora } \\
\text { Sp. }\end{array}$ & $\begin{array}{l}\text { Rhisopus } \\
\text { Nigricans }\end{array}$ \\
\hline $\mathrm{TFQ}$ & 66 & 81 & 73 & 74 \\
\hline $\mathrm{Cu}^{2+\mathrm{TFQ}}$ & 86 & 90 & 91 & 85 \\
\hline $\mathrm{Ni}^{2+} \mathrm{TFQ}$ & 68 & 84 & 87 & 88 \\
\hline $\mathrm{Co}^{2+\mathrm{TFQ}}$ & 78 & 86 & 78 & 81 \\
\hline $\mathrm{Mn}^{2+} \mathrm{TFQ}$ & 76 & 87 & 81 & 78 \\
\hline $\mathrm{Zn}^{2+\mathrm{TFQ}}$ & 74 & 91 & 86 & 76 \\
\hline
\end{tabular}

\section{Conclusion}

Tannin is good monomer for polymerization with formaldehyde. Tannin was copolymer with formaldehyde and 8hydroxy quinoline (a chelating agent). The copolymer was designated as TFQ then its various transition metal chelating 
were prepared and characterized. The chelates are thermally stable and have good antifungal activity. Overall the TFQ resin can be good metal precipitant and is could be used for extraction of metals from ores.

\section{Compliance with ethical standards}

\section{Acknowledgments}

We wish to acknowledge the facilities and support provided by Management, SNR Trust, and Dr.B.L Sivakumar, Secretary and Principal, Sri Ramakrishna College of Arts and Science, Coimbatore for allowing us to use chemistry Research Laboratory for our synthesis.

\section{Disclosure of conflict of interest}

The authors have no conflict of interest.

\section{References}

[1] Ciesilski T., Pastukhov M.V., Szefer P., Jensen B.M., Bioaccumulation of Mercury in the pelagic food chain of lake Baikal, Chemosphere.1984;78: 1378-1389.

[2] Loukidou,M.X., A.I.Zouboulis, T.D. Karapantsios and K.A. Matis, Physiochemical and Engineering Aspect. 2004 ;242(89): 93- 104.

[3] B.A. Shah, A.V. Shah, B.N. Bhandaria, R.R. Bhatt,Synthesis, Characterization and Chelation Ion-Exchange Studies of a Resin Copolymer Derived from 8-Hydroxy quinoline -Formaldehyde-Catechol. J. Iran. Chem. Soc. 2008; 5(2): $252-261$.

[4] D.T. Masram, K.P. Kariya, N.S. Bhave, : Electrical conductivity study of resin synthesized from salicylic acid, butylenediamine and formaldehyde. Arch. Apll. Sci. Res. 2010; 2 (2): 153-161.

[5] Gurnule W.B and Thakre M. B. Synthesis and Characterization of High Performance Terpolymer Resin Derived from 8- Hydroxyquinoline and Adipamide, Scholars Research Library, Der Pharma Chemica. 2011; 3 (6): 235242.

[6] Raj. J.A., Vedhi. C., Burkanudeen A., Arumugam P. and Manishankar P. Synthesis and characterization of novel nano-size, Poly Reactive. 2010; 16: 171-175,

[7] Shah B.A., Shah A.V. and Bhatt R.R. Studies of chelation ion-exchange properties of copolymer resin derived from salicylic acid and its analytical applications, Iranian Polym. J. 2007; 16(3): 173-184.

[8] JC Patel, HR Dholariya, KS Patel, KD Patel, Appl. Organomett, Chem. 2012; 26(24): 604-610.

[9] Gurnule W.B. and Bisen V. R., Kinetics of Thermal Decomposition of Copolymer Resin-II Derived from 4hydroxylbenzaldehyde, Phenyl hydrazine and Formaldehyde. Research Journal of Pharmaceutical, Biological and Chemical Sciences. 2014; 5(4): 1283-1298,.

[10] Pan J., Plant J. A., Voulvouliis N. Oater C. J., Ihlenfeld C., Cadmium Levels, In Europe: Implication for human health, Environ. Geochem. Health .2010; 32: 1 - 12.

[11] Vilayatkar N.D., Gadegone S.M. and Rahangdale P.K., Removal of Carcinogenic Cr(Vi) Using Cajanus Cajan Pericarp Activated Carbon , International Journal of Recent Scientific Research Research. 2014; 5(9): 1654-1657.

[12] CD Doyel, "Quantitative calculations in thermogravimetric analysis" Marcel Dekker, Inc., New York. 1966; 32 : 287-312.

[13] WR. Baily, EG Scott, C V Moshy Co.St.Lovis, Diagnostic Microbiology.1966; $\quad$ 12(7): 257.

[14] Kumar, A. Praveen; Reddy, P. Raveendra and Reddy, V. Krishna Indian Journal of Chemistry., 2007, 46, 16251629. 